\title{
Genetic characterization of Trypanosoma cruzi natural clones from the state of Paraíba, Brazil
}

\author{
Christian Barnabé/ ${ }^{+}$, M Tibayrenc, Carlos Brisola Marcondes*
}

\begin{abstract}
Génétique et Evolution des Maladies Infectieuses, Unité Mixte de Recherche Centre National de la Recherche Scientifique, Institut de Recherche pour le Développement 2724, IRD, BP 64501, 34394 Montpellier Cedex 05, France *Departamento de Microbiologia e Parasitologia, Centro de Ciências Biológicas, Universidade Federal de Santa Catarina, Florianópolis, SC, Brasil
\end{abstract}

Eighteen Trypanosoma cruzi stocks from the state of Paraíba, Brazil, isolated from man, wild mammals, and triatomine bugs were studied by multilocus enzyme electrophoresis and random primed amplified polymorphic DNA. Despite the low number of stocks, a notable genetic, genotypic, and phylogenetic diversity was recorded. The presence of the two main phylogenetic subdivisions, T. cruzi I and II, was recorded. The strong linkage disequilibrium observed in the population under survey suggests that $\mathrm{T}$. cruzi undergoes predominant clonal evolution in this area too, although this result should be confirmed by a broader sample. The pattern of clonal variation does not suggests a recent origin by founder effect with a limited number of different genotypes.

Key words: Trypanosoma cruzi - Triatoma pseudomaculata - Triatoma brasiliensis - Didelphis albiventris - multilocus enzyme electrophoresis - random primed amplified polymorphic DNA - Chagas disease - Paraíba - Brazil

Trypanosoma cruzi, the causative agent of Chagas disease, is a flagellate protozoon of major medical importance in Central and South America. Since 1975, when the National Chagas Control program was initiated in Brazil, the transmission of the disease has tremendously decreased in this country. In 1993, focal areas still infested with Triatoma infestans, persisted in the states of Bahia, Tocantins, and Rio Grande do Sul (WHO 1997). The incidence of the disease decreased from $3.5 \%$ in 1980 to $0.36 \%$ in 1994 for the state of Paraíba and from 4.2 to $0.15 \%$ for all the states. Nevertheless, a recent study (Coura et al. 1996) has shown that $5.5 \%$ of Triatoma brasiliensis, another important vector in Brazil, were infected with T. cruzi in domiciliary and peridomiciliary areas in the state of Piauí near Paraíba. In the same region, others (Bento et al. 1992) have reported a high level of infection $(22.6 \%)$ of captured triatomine bugs by flagellates that were morphologically similar to $T$. cruzi, suggesting that in these regions an active transmission of Chagas disease could still occur.

T. cruzi stocks from Northeast of Brazil were among the first to be genetically characterized by means of isoenzymes and led to the description of three main zymodemes circulating in Brazil (Miles et al. 1978). However, little is known about the specific $T$. cruzi genotypes circulating in the state of Paraíba and the population structure of the parasite in that area. The aim of the present work was

Financial support: Finep process 43.86.0736.00, Universidade Federal da Paraíba

+Corresponding author. E-mail: Christian.Barnabe@mpl.ird.fr Received 10 September 2004

Accepted 6 April 2005 therefore to explore these different points by means of multilocus enzyme electrophoresis (MLEE) and random amplified polymorphic DNA (RAPD) markers.

Eighteen stocks were isolated in the state of Paraíba: 4 stocks, CA-1 01/05, CA-2 01/03, were isolated from $T$. pseudomaculata in the locality of Camalau in 1987; 3 stocks, CARV-2 01/02/03, from T. brasiliensis at Camalau in 1987; 5 stocks, G38 01/02/03/04 and G-54 02, from Didelphis albiventris in Camalau in 1988; 2 stocks, G49 01/04, from $D$. albiventris in the locality of Alagoa, in 1988; 1 human stock, X-300, from the locality of Monteiro in 1989; and 3 other human stocks, X-146 X-395 01/02 from unknown locality. Five reference $T$. cruzi stocks previously characterized (Barnabé et al. 2000), were selected to be representative of the whole phylogenetic diversity: Cuicacl1 and Tehcl2 as T. cruzi I (TC I); CANIIIcl1 as T. cruzi IIa (TC IIa); TU18cl2 as T. cruzi IIb (TC IIb), and SC43cl1 as T. cruzi IId (TC IId). Numering I, IIa, etc, corresponds to the Discrete Typing Units (DTU) described by us (Barnabé et al. 2000). Enzyme electrophoresis on acetate cellulose plates was performed on twenty enzyme systems as previously described (Ben Abderrazak et al. 1993). PCR-RAPD were performed according to Williams et al. (1990) by using 13 primers (A1, A2, A4, A7, A8, A9, A10, A12,A15, A17, A18, A19, and A20) from the kit A of Operon Technologies, Alameda, CA. The genetic divergence between stocks was estimated by the Jaccard's distance and the UPGMA method (unweighted pair group method with arithmetic averages) was used to cluster the stocks. The software package PHYLIP (Felsenstein 1989) was used for phylogenetic and bootstrap analysis. Different indices of genetic polymorphism were used, for a review see Barnabé et al. (2000). To explore the population structure of $T$. cruzi, we used the statistical tests proposed by Tibayrenc et al. (1990), based on linkage disequilibrium analysis. Strong levels of linkage disequi- 
librium are a mark of lack of genetic recombination and are taken as circumstantial evidence of a clonal population structure. The ways to detect biases due to geographical and/or temporal separation (Wahlund effect) were previously exposed (Tibayrenc et al. 1991). The tests were applied to the whole sample and to different subsets of it, by different localities or different genetic clusters.

The Table gives the results of diversity indices, genetic distances and population genetic tests. Only one locus was monomorphic, the others were polymorphic ranging from 2 to 6 different genotypes, with a mean of 3.3 different genotypes per locus. Among the Paraíba stocks, 9 distinct MLEE multilocus genotypes and 10 distinct RAPD multilocus genotypes were found. The UPGMA trees built from either MLEE (Figure) or RAPD (data not shown) showed two main clusters, one included the TC I reference stocks, the other included the TC II reference stocks. In the T. cruzi I cluster, the 16 Paraíba stocks constituted a distinct subcluster. Only two human stocks from Paraíba were clustered in TC II. This overall clustering pattern was fully confirmed by RAPD (data not shown). In order to remove the bias introduced in the linkage disequilibrium tests by sampling identical genotypes from the same host, we have taken into account, for each individual host, those multilocus genotypes that appeared different from each other only. The genetic distances recorded among these stocks were high and most linkage disequilibrium tests were highly significant.

In spite of the limited number of stocks, we have been able to record a non negligible genetic and genotypic variability in this sample. As shown in the Table, the indices are notably higher than the ones recorded in another Brazilian region, the state of Paraná (Soccol et al. 2002). This remain true even when only the stocks belonging to the main cluster are taken into account. These results enter the framework of the present state of knowledge on $T$. cruzi phylogenetic diversity (Momen 1999) and show that both TC I and II are represented in the Paraíba region contrary to the state of Paraná (Soccol et al. 2002), where only TC I was found. The results of the linkage disequilibrium tests suggest that the pattern of a basically clonal population structure (Tibayrenc et al. 1986) with rare hybridization events (Machado \& Ayala. 2001, Gaunt et al. 2003) recorded in all other Chagas cycles, is verified in this area too. The tests have been also performed only on those stocks pertaining to the main cluster to take into account the possible working hypothesis that the two clusters correspond to two separate sexual species (Maynard Smith et al. 1993). Again in the present sample, several tests remain highly significant when we followed

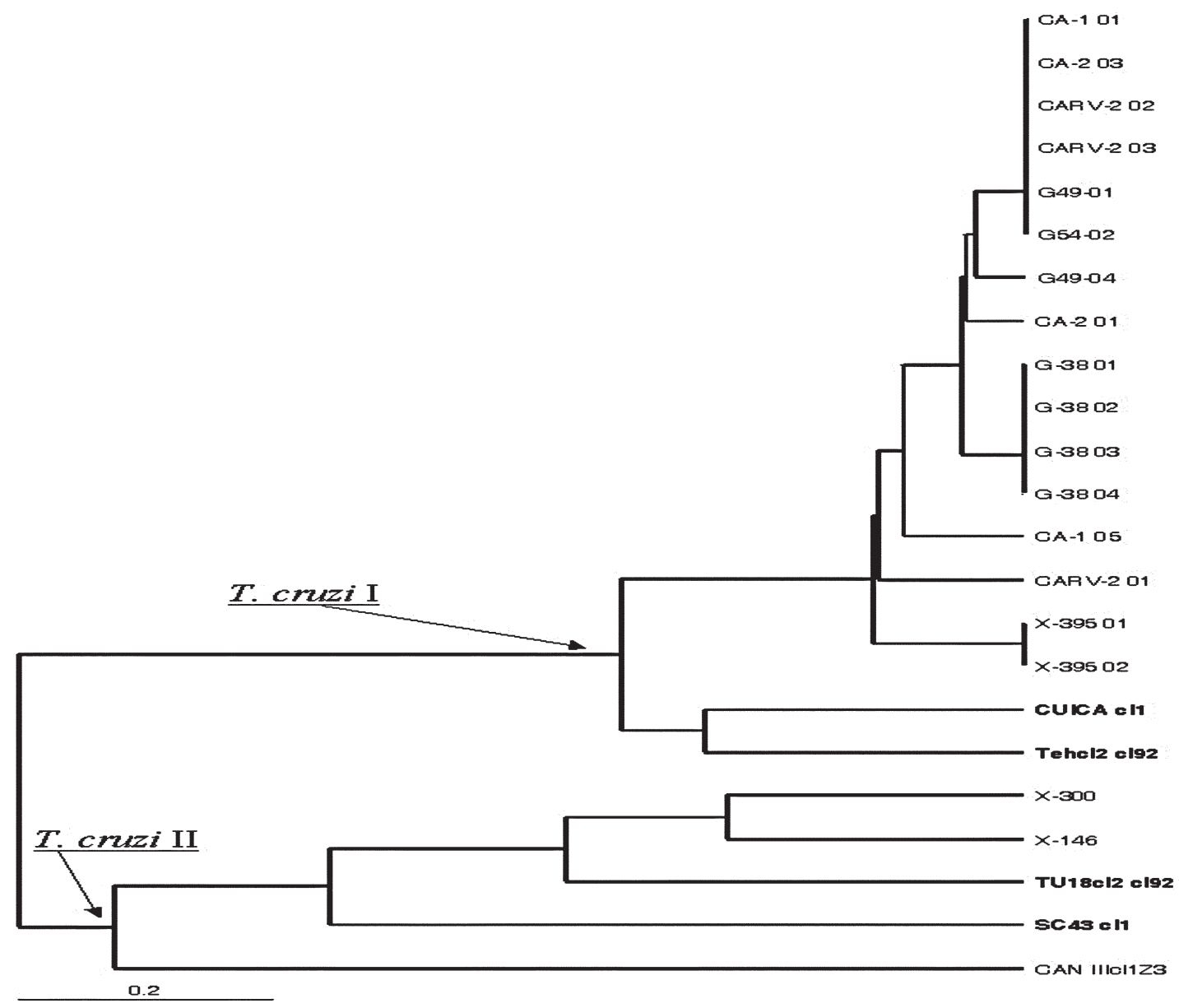

Dendrogram constructed with the unweighted pair group method with arithmetic averages, depicting the phylogenetic relationships based on multilocus enzyme electophoresis, among the 18 Trypanosoma cruzi stocks under survey. 
TABLE

Genetic variability indices and results of linkage disequilibrium tests recorded among the Trypanosoma cruzi stocks from the state of Paraíba and comparison with T. cruzi stocks from the state of Paraná (Soccol et al. 2002)

\begin{tabular}{|c|c|c|c|c|c|c|c|c|c|c|c|}
\hline \multirow[t]{2}{*}{ Sample } & $\operatorname{Size}^{a}$ & Marker & PR & MGD & GD & $\mathrm{MaD}$ & $\mathrm{MD}+\mathrm{SD}$ & d1 & d2 & $\mathrm{e}$ & $\mathrm{f}$ \\
\hline & \multicolumn{7}{|c|}{ Variability indices } & \multicolumn{4}{|c|}{ Recombination test results } \\
\hline Paraiba & 13 & MLEE & 0.82 & 0.23 & 0.69 & 0.73 & $0.22 \pm 0.28$ & $2.96 \mathrm{E}-5$ & $<1 \mathrm{E}-4$ & $<1 \mathrm{E}-4$ & $<1 \mathrm{E}-4$ \\
\hline Paraiba $^{b}$ & 9 & MLEE & 0.82 & 0.29 & - & 0.73 & $0.30 \pm 0.29$ & - & - & - & $<1 \mathrm{E}-4$ \\
\hline Paraiba & 14 & RAPD & 1 & 0.47 & 0.71 & 0.80 & $0.29 \pm 0.29$ & $1.17 \mathrm{E}-6$ & $<1 \mathrm{E}-4$ & $<1 \mathrm{E}-4$ & $<1 \mathrm{E}-4$ \\
\hline Paraiba $b$ & 10 & RAPD & 1 & 0.58 & - & 0.80 & $0.38 \pm 0.29$ & - & - & - & $<1 \mathrm{E}-4$ \\
\hline Camalau & 8 & MLEE & 0.14 & 0.04 & 0.62 & 0.11 & $0.04 \pm 0.03$ & 0.58 & 0.68 & 1 & 0.69 \\
\hline Camalau $^{b}$ & 5 & MLEE & 0.14 & 0.06 & - & 0.11 & $0.06 \pm 0.03$ & - & - & - & 0.76 \\
\hline Camalau & 9 & RAPD & 0.61 & 0.20 & 0.55 & 0.22 & $0.08 \pm 0.08$ & $1.15 \mathrm{E}-2$ & $2 \mathrm{E}-4$ & $<1 \mathrm{E}-4$ & $<1 \mathrm{E}-4$ \\
\hline Camalau $^{b}$ & 5 & RAPD & 0.61 & 0.26 & - & 0.22 & $0.12 \pm 0.07$ & - & - & - & $5.1 \mathrm{E}-3$ \\
\hline T. cruzi I & 11 & MLEE & 0.23 & 0.05 & 0.77 & 0.11 & $0.04 \pm 0.03$ & 0.56 & 0.62 & 1 & 0.71 \\
\hline T. cruzi I & 12 & RAPD & 1 & 0.31 & 0.66 & 0.33 & $0.12 \pm 0.09$ & $1.38 \mathrm{E}-3$ & $<1 \mathrm{E}-4$ & $<1 \mathrm{E}-4$ & $5 \mathrm{E}-4$ \\
\hline T. cruzi $\mathrm{I}^{b}$ & 8 & RAPD & 1 & 0.40 & - & 0.33 & $0.17 \pm 0.08$ & - & - & - & $5.4 \mathrm{E}-3$ \\
\hline Paraná $^{c}$ & 31 & MLEE & 0.09 & 0.03 & 0.01 & 0.11 & $0.04 \pm 0.04$ & ND & ND & ND & ND \\
\hline
\end{tabular}

$a$ : size of the sample after removing the identical multilocus genotypes in stocks isolated from the same individual host; $b$ : on the different multilocus genotypes only; $c$ : previous results from Soccol et al. (2002); PR: polymorphism rate at 95\%; MGD: mean genetic giversity; GD: genotypic diversity; MaD: maximum genetic distance; $\mathrm{MG}+\mathrm{SD}$ : mean genetic distance \pm standard deviation; -: aimless; ND: not done; d1, d2, e, and f: recombination tests proposed by Tibayrenc et al. (1990).

this procedure. One test remains highly positive even when only the different genotypes instead of the stocks are counted in the main cluster as recommended by Maynard Smith et al. (1993) to distinguish between long-term clonal evolution epidemic clonality. However, a broader sample should be surveyed in this area in order to fully confirm the result of a predominant clonal population structure.

\section{REFERENCES}

Barnabé C, Brisse S, Tibayrenc M 2000. Population structure and genetic typing of Trypanosoma cruzi, the agent of Chagas disease: a multilocus enzyme electrophoresis approach. Parasitology 120: 513-526.I

Ben Abderrazak S, Guerrini F, Mathieu-Daude F, Truc P, Neubauer K, Lewicka K, Barnabé C, Tibayrenc M 1993. Isoenzyme electrophoresis for parasite characterization. In JE Hyde, Methods in Molecular Biology, Humana Press Inc., New York, p. 361-382.

Bento DN, Farias LM, Godoy MF, Araujo JF 1992. The epidemiology of Chagas' disease in a rural area of the city of Teresina, Piauí, Brazil. Rev Soc Bras Med Trop 25: 51-58.

Coura JR, Borges-Pereira J, Alves Filho FI, de Castro JA, da Cunha RV, Costa W, Junqueira AC 1996. Morbidity of Chagas disease in areas of Sertão da Paraíba and Caatinga do Piauí. Rev Soc Bras Med Trop 29: 197-205.

Felsenstein J 1989. PHYLIP - Phylogeny Inference Package (Version 3.2). Cladistics 5: 164-166.

Gaunt MW, Yeo M, Frame IA, Stothard JR, Carrasco HJ, Taylor MC, Mena SS, Veazey P, Miles GA, Acosta N, De Arias AR, Miles MA 2003. Mechanism of genetic exchange in American trypanosomes. Nature 421: 936-939.

Machado CA, Ayala F J 2001. Nucleotide sequences provide evidence of genetic exchange among distantly related lineages of Trypanosoma cruzi. Proc Natl Acad Sci USA 98: 7396-7401.
Maynard Smith J, Smith N H, O’Rourke M, Spratt BG 1993. How clonal are bacteria? Proc Natl Acad Sci USA 90: 43844388 .

Miles MA, Souza A, Povoa M, Shaw JJ, Lainson R, Toye PJ 1978. Isozymic heterogeneity of Trypanosoma cruzi in the first autochthonous patients with Chagas' disease in Amazonian Brazil. Nature 272: 819-821.

Momen H 1999. Taxonomy of Trypanosoma cruzi: a commentary on characterization and nomenclature. Mem Inst Oswaldo Cruz 94: 181-184.

Soccol TV, Barnabé C, Castro E, Luz E, Tibayrenc M 2002. Trypanosoma cruzi: isoenzyme analysis suggests the presence of an active Chagas sylvatic cycle of recent origin in Paraná state, Brazil. Exp Parasitol 100: 81-86.

Tibayrenc M, Kjellberg F, Arnaud J, Oury B, Brénière S F, Darde M L, Ayala FJ 1991. Are eukaryotic microorganisms clonal or sexual? A population genetics vantage. Proc Natl Acad Sci USA 88: 5129-5133.

Tibayrenc M, Kjellberg F, Ayala FJ 1990. A clonal theory of parasitic protozoa: the population structures of Entamoeba, Giardia, Leishmania, Naegleria, Plasmodium, Trichomonas, and Trypanosoma and their medical and taxonomical consequences. Proc Natl Acad Sci USA 87: 24142418.

Tibayrenc M, Ward P, Moya A, Ayala FJ 1986. Natural populations of Trypanosoma cruzi, the agent of Chagas disease, have a complex multiclonal structure. Proc Natl Acad Sci USA 83: 115-119.

WHO 1997. Chagas disease. Interruption of transmission. Weekly Epidemiol Rep 72: 1-4.

Williams JGK, Kubelik AR, Livak KJ, Rafalski JA, Tingey SV 1990. DNA polymorphisms amplified by arbitrary primers are useful as genetic markers. Nucleic Acids Res 18: 6531-6535. 
